$\longrightarrow \quad$ LECT URES ox

\section{THE PRACTICE OF MEDICINE.}

BY

CHARLES MURCHISON, M.D., LL.D., F.R.S.,

Physician to St. Thomas's Hospital, and Joint Lecturer on Medicine at St. Thomas's Hospital Medical School; etc.

LECTURE I.--INTRODUCTORY. (Conclucled.)

Arultiplicity and Nomenclature of Diseases. - Plan of Course. 1. Definitions of Disease. 2. Etiology: A. Predisposing Caneses; B. Exciting. 3. Mrorbid Anatomy and Chemistry. 4. Symptoms: Subjectize and Objectize. Modis of Dying. 5. Varietics of Discase. 6. Complications and Sequele. 7. Diagnosis. 8. Progreosis. 9. Treatment: A. Pro. phylactic; B. Cucrative.

V. Varicties.-The phenomena of the same disease, or, to speak more plainly, groups of symptoms originating from a common cause, may vary greatly under different conditions, or according to accidental circumstances. A knowledge of these varieties is essential to correct diagnosis. The varieties of some diseases are so well marked, that they will demand our particular attention. The remarkable differences presented by small-pox, according as the eruption is discrete or confluent, or as the disease occurs in a person protected or not by vaccination; the no less striking contrast between a mild and a malignant case of scarlet fever ; and the numerous varieties assumed by ague and enteric fever, may be cited as illustrations.

VI. Complications and Sequelc. -Diseases are often spoken of as either primary or secondary. Secondary, or as they are sometimes termed, intercurrent diseases, are those which occur in the course of the primary disease, and usually owe their origin to it, although sometimes they result from the same cause as the primary disease, or acci. dentally coexist with it. When secondary diseases accompany or follow the primary disease, the latter is said to be complicated, and the second. ary diseases are termed complications or sequela. Few acute diseases run their course without the occurrence of such complications; and not uncommonly the primary disease sinks into insignificance beside the complication which it has excited, and may even run the risk of not being recognised. In many diseases, also, one of the chief duties of the medical attendant is to be on the look out for these cumplications, and to endeavour to avert them. It will, therefore, be incumbent upon me to point out to you under the head of each disease what are the complications most likely to occur. The cardiac complications of acute rheumatism, the renal complications of scarlet fever, the pulmonary complications of typhus, and the many complications of kidney-diseases, are good illustrations of what I have now said.

I have stated that few acute diseases run their course without the occurrence of complications ; but perhaps it would be more correct to say that, if we except those acute diseases which owe their origin to a specific poison, there are few acute diseases which are not themselves secondary to chronic derangements of structure and function in different organs. You will constantly hear it remarked that a person has died suddenly of apoplexy or of water on the brain (tubercular meningitis). Both of these diseases undoubtedly run an acute course, and cut life short suddenly, but both are secondary to chronic changes in structure and nutrition. In the instances that I have quoted, the secondary nature of the acute attacks is to the medical observer sufficiently patent but hereafter I shall have occasion to point out to you that there is reason for believing, that most of the acute local diseases are really secondary to pre-existing chronic derangements of nutrition and structure.

VII. Diagnosis. - By diagnosis we understand the recognition of the real cause of a patient's symptoms, or the discrimination of one disease from another. The diagnosis of diseases characterised by pathogno. monic signs is comparatively easy ; but in the absence of such signs, the skill of a physician is never better displayed than in interpreting aright the import of symptoms. In many diseases, the symptoms occa. sionally so closely approximate those of others with which they have no connection, that an accurate diagnosis is no easy matter; and therefore it becomes necessary that I should mention to you, as we go along, the diseases most likely to be confounded, as well as the main rules for your guidance in deciding between them. If you wish to be successful practitioners of medicine, you must from the first make diagnosis one of the main objects of your study. It requires no medical education to treat symptoms, as the homcopathist does; the object of all medical education is to enable you to recognise and treat the disease on which the symptoms depend. Errors in diagnosis, also, when discovered, are often visited by the public with greater punishment than they deserve; but, putting aside any such consideration, they ought to make every medical man cross-examine himself to see whether by any possibility they could have been avoided. Accuracy of diagnosis, in fact, lies at the foundation of rational medicine, and is indispensable for forming correct conclusions as to the effects of treatment. Erroneous conclusions on this point are too often based upon a wrong diagnosis. When it is gravely stated that such diseases as scarlet fever, diphtheria, and cholera cease to be fatal, and that even cancer is curable, under some particular line of treatment, it is clear to any medical man of common sense and experience that the statement is either a pure invention, or that it has arisen from some error in diagnosis.

VIII. Prognosis is the term applied to the art of predicting the duration, course, and probable mode of termination of a disease. To the medical practitioner, accuracy in prognosis is secondary in importance only to diagnosis and treatment, and too often his duty is for the most part restricted to foretelling the probable result, without much power on his part to prevent or postpone it. "To my mind," wrote Hippocrates many centuries ago, "he is the best physician who knows beforehand what is going to happen. By penetrating into, clearly describing the present and the future of the maladies of his patients, and explaining symptoms which they omit to state, he will gain their confidence. Convinced of his superior intelligence, they will unhesitatingly place themselves under his direction. It is impossible to restore every patient to health, but the prediction of the succession of symptoms will be even more highly appreciated. It is of importance to recognise the nature of similar affections, to know the extent to which they exceed the constitutional power, and likewise to discern when there is any supernatural element in the disease ; for that is a point which affects the prognosis. It is in this way that the physician will obtain the merited need of admiration, and practise his profession with ability. Knowing the cases which are curable, he will be the better able to guard his patients from danger, by indicating the precautions to be taken against each untoward contingency; and by foreseeing and predicting fatal and favourable issues, he will escape blame."

In forming a prognosis, several circumstances require to be taken into consideration.

I. The known rate of mortality of the particular disease. Take, for instance, relapsing fever and typhus. The prognosis will be much more favourable in the former-in which the rate of mortality is only 2 or 3 per cent. - than in the latter, in which the mortality is as high as 20 per cent.

2. The circumstances known to influence the rate of mortality, such as the age, constitution, and habits of the patient, and the stage at which the malady has arrived. For example, in typhus fever, the mortality in persons between 10 and 15 years of age is not much over 2 per cent., but in persons over 50 it exceeds 50 per cent. Accord. ingly, the prognosis even at the commencement of an attack of typhus would be at least twenty times more unfavourable in the latter period of life than in the former. Again, the natural duration of urcomplicated typhus being fourteen days, and the symptoms and other conditions being alike in two cases on the tenth and fourteenth days respectively, the prognosis would be much more favourable in the case where the disease had reached its natural limit, than in that in which there were four days still to run.

3. The presence of certain symptoms and complications influences the prognosis. In many oiseases there are certain symptoms which, from their severity or very occurrence, are of grave prognostic import. Of this nature are convulsions in typhus, hæmorrhages in small-pox, and a gangrenous odour of the breath in pneumonia. As a rule, com. plications add to the severity and danger of the primary disease.

The science of prognosis comprises not merely the forecasting the probable duration and mode of termination of a particular malady, but also the calculation of an individual's chances of longevity from a due consideration of his personal and family medical history, and from an examination of the condition of his internal organs. Prognosis, whether in ordinary medical practice, or for deciding as to the eligibility of an individual for life-assurance, must be based on an intimate knowledge of the natural history of disease. Considering the great importance of the subject, it is remarkable how little special attention has been devoted to it. While there are numberless works on pathology, diagnosis, and therapeutics, no special work on the general subject has appeared since the "Prognostics" of Hippocrates. At present, skill in prognosis is confined to 2 few members of our profession, who have been close observers of nature and had great experience, but this knowledge dies with the individual. A rigid analysis of ascertained facts, with the view of arriving at something like definite conclusions as to prognosis in different diseases, is still a desideratum in medical literature. 
IX. Treatment. - The treatment of disease is, or ought to be, the chief end of all medical study. It may be considered under the two heads of prophylaxis and cure-the former consisting in the removal of those causes which are known to favour the origin of disease, and the latter in the application to individual cases of the resources of pharmacy and hygiene.

$$
\text { A.-Prophylactic Triatmint. }
$$

Many diseases are far more easily prevented than cured. The importance of studying the causes of disease has been already insisted on ; and you cannot fail to see that to know the cause of a disease is in many instances to know how to prevent it. This remark applies with special force to the diseases dependent on a morbific poison ; for when the laws determining the origin and diffusion of these poisons are accurately known, it will be possible, by proper precautions, to extirpate them completely, and the most loathsome of the diseases belonging to this class we have already the power to eradicate by the simple operation of vaccination. But it is not alone for these diseases that prophylaxis may be resorted to. By carefully studying the peculiarities and morbid proclivities of each individual, the medical man can do much to prevent the development of those slow functional and structural changes which we have found to lie at the foundation of most fatal diseasesboth acute and chronic; and, in the event of these changes being already developed, he can point out the conditions likely to increase them or to excite fresh disease, and exposure to which it is necessary to avoid. The abolition of scurvy from our royal and merchant navies is one of the greatest triumphs of prophylactic medicine. The study of prophylaxis is still in its infancy, but enough has been done to justify the expectation that the future is pregnant with great discoveries in this direction. It is one of the glories of our profession that all the great discoveries in the prophylaxis of disease have been made by medi. cal men, who in the most disinterested manner are constantly instilling into the public mind the first principles of Preventive Medicine. It is to be hoped that the time is not far distant when the public will consult their own best interests by applying to medical men for counsel and advice to aid them in preventing, as well as in curing, disease.

\section{B. - Curatize Triatulent.}

But when disease is already present, there is a two-fold treatment to be adopted-hy'sientic and thicrapeutic, the former consisting in placing the patient in those hygienic conditions which are known to be most conducive to a natural recovery; and the latter, in aiding recovery by the judicious administration of medicines.

a. The hygricnic treatment involves a scrupulous attention to cleanliness, regulation of the diet, and of the cubic space and ventilation of the sick room in accordance with the peculiarities of each case, in sometimes enjoining absolute rest, as in cerebral apoplexy or peritonitis from suspected perforation; in witholding food from an ulcerated stomach; in forbidding the visits of friends in certain cases of delirium ; in removing the cause, where this is possible, as in neuralgia from a decayed tooth; and at all times, when the circumstances seem to justify such a course, in inspiring confidence and holding out encouragement and hope. Attention to these so-called "little" matters is often of greater moment than all the drugs in the Pharmacopceia.

$b$. The most superficial student of medicine will not be long in perceiving that the therapeutical treatment of disease has of late years undergone a great revolution. Half a century ago, it was the universal fashion to commence the treatment of all acute diseases by taking blood, more or less largely, and by employing other depleting measures, with a diet bordering on absolute starvation; but at the present day in this country venesection is a rarer operation than lithotomy or amputation at the hip-juint, while leeches and cupping are not once employed for five hundred times that they were resorted to in former days. It has been the custom with many to account for this revolution in medical practice, by supposing that a "change in the type of disease" has necessitated a corresponding change in treatment. It has been con. tended that in recent years diseases have been of a more asthenic type than formerly. Continued fevers and inflammation of the lungs have been the diseases with regard to which the battle of change of type has been mainly fought; but a careful study of their history fails, in my opinion, to lend any support to the theory in question, after making every allowance for any constitutional change resulting from alterations in the habits of the population. * In many parts of the Continent, also, it is still the fashion to treat acute diseases, and even fevers, with bleed. ing and a starvation diet; but no one could argue that this difference in practice is justified by a difference in the type of disease. The revolu. tion in practice referred to must be ascribed to a sounder knowledge of

* See a memoir by author, "On the Supposed Changes in the Type of Continued Fevers." - Edinburgh Medical Fournal, August 1858 . pathology. Formerly, when a fever or inflammation made its appearance, it was looked upon as something superadded to the organism, as an enemy attacking the fortress of life, who required the most energetic measures for his repulsion. It was thought necessary to cut off his supplies by the enforcement of a rigorous diet, and to attack him with the heavy artillery of bleeding, mercury, and blisters. It was forgotten that these nieasures weakened the garrison equally with the enemy, if not more so, and that, even if the latter were overcome, the patient often succumbed, owing rather to the severity of the treatment, than to the malignancy of the disease. * Iut now we look upon diseases as merely perversions of normal structure and functions, and oitr treatment accordingly consists in putting the part or the system in the circum. stances most favourable for the resumption of its physiological condition. But in doing this, we must beware of rushing into the opposite extreme of over-stimulation. The consequences of overcrowding the garrison may be as injurious as bombarding it with the heavy artillery already referred to.

As regards the treatment of disease, there are some instructions which I am desirous to impress upon your minds at the outset.

1. You must at once disabuse your minds of the common notion that diseases are distinct entities, for which medical men possess antidotes in the shape of physic. The idea is a priori improbable, and is not supported by facts. Ague, gout, syphilis, scurvy, and periosteal inflammation are the only maladies for which we possess anything like specific remedies, and even from this short list many would exclude all but the first. In the present state of our knowledge, the medical man who makes it understood that he has specific remedies for scarlet fever, typhus, consumption, or cancer, has either deceived himself or is de. ceiving others. The treatment of these and of most other diseases must be conducted according to the symptoms and constitutional peculiarities in each individual case. You must regard medicines not as antidotes to disease, but simply as means for the relief of symptoms, and for aiding the vis medicatrix naturce in conducting the disease to a favourable termination.

2. Although medical skill and judgment will sometimes be best displayed in abstaining from the administration of drugs, you must beware of falling into the error of adopting a purely expectant treatment, or of leaving diseases, so far as drugs are concerned, entirely to nature. Un. limited scepticism in this matter is, in my opinion, as dangerous as unlimited credulity.

3. You must not object to employ remedies recommended on purely empirical grounds, simply because you may be unable to explain their
mode of action. By doing so, you will deprive the patient of some of the most valuable remedies which we possess.

4. You must not allow prejudice to blind your eyes against certain remedial measures recommended by good authority, simply because they may have originated among homœopathists, hydropathists, kinesipathists, or other heterodox practitioners. Although the doctrines of infinitesimal doses, and of "similia similibus curantur" may be utterly fallacious, it is to the strong advocacy of homneopathists that we are indebted for the common use of more than one excellent remedy : and homceopathy must also be to some exter:t credited for directing attention to the affinities, or predilections of certain drugs for particular tissues or parts of the body, a subject where careful investigation may be expected to lead to great results. Again, those who keep pace with advancing medical knowledge cannot shut their eyes to the fact that we are indebted to hydropathy for the most certain means which we possess of reducing temperature in cases of extreme pyrexia. And, lastly, there can be no doubt that certain cases of paralysis are benefited by kinesi. pathy, or the movement-cure, when all other methods of treatment have been found useless.

5. You must lose no opportunity of carefully noting the effects of drugs upon the symptoms of disease. There is no department of medical science which has been more neglected, or which more urgently calls for careful and philosophical investigation, than the effects of drugs upon the human body in health and in disease, as tested by the accurate means of research which we now possess. Enough has been done within the last few years to justify great expectations for the future.

Meanwhile medical science has already achieved enough to deserve the lasting approbation of mankind. Because it cannot effect impossibilities, and eradicate from the world disease and death, it is from time to time held up to ridicule as undeserving the great reputation it has acquired. But surely it is no small matter to have reduced the average annual mortality from 44 to 27 per thousand in England during the last quarter of a century, to have shown how such diseases as scurvy, small-pox, typhus, and enteric fever may be prevented, to be alsle to annul the pains of parturition and of surgical operations, to induce

* On this, see Haldane, in Ealinburg's Medical Jourral, February 1865. 
tranquil sleep in maniacal delirium, and to remove or relieve many other distressing symptoms without in any way impairing the patient's constitution, or thwarting the natural tendency to recovery.

From what I have stated, you cannot fail to perceive that to carry out successfully the medical treatment of disease, a scientific knowledge of diseases in all their bearings, and an intimate acquaintance with the patient's constitution, are absolutely necessary. Rational medicine, the principles of which I shall endeavour in these lectures to teach to you, differs from quackery in not professing to have an antidote for every disease in the nosology, and in its basis being, not physic, lout anatomy, physiology, chemistry, pathology, and therapeutics. It ought also to differ from it in affecting no mystery, and in perfect honesty of purpose.

\section{CLINICAL LECTURE}

\author{
or
}

\section{EXCISION OF THE HEAD AND NECK OF THE FEMUR IN CASES OF HIP-JOINT DISEASE. \\ Delivered in the Glasgow Royal Infirmary.}

BY JAMES MORTON, M.D.,

Surgeon, and one of the Clinical Lecturers in the Hospital.

IN the surgical history of the past year there is one subject which, more than most others, has attracted my attention and cost me some thought, so that it is not unnatural that I should consider it proper to draw your attention to it ; I refer to excision of head of the femur as a remedy for the disease usually styled morbus coxx, or disease of the hip-joint.

It is at present quite unnecessary to refer to the general subject of the excision of joints, not a few of the articulations of the body being the recognised fields for such resections. With the hip it has been different; and although the operation has been occasionally performed, the success has been so limited as to discourage those who have attempted it. I have been witness to abortive efforts on the part of several eminent surgeons, the cases generally ending fatally.

A considerable time ago (eight or ten years), I happened to have in these wards a girl who had been the subject of morbus coxæe, one of whose legs became so fixed as to impede the motion of the other, so that it became very desirable that some change should be effected in her condition. To uccomplish this, excision of the head of the femur was performed, and with entire success, the patient (a mill-worker) being soon able to return to her usual occupation. Some years afterwards, this girl was again admitted into the Infirmary, this time into the medical wards, suffering from albuminuria, of which she soon died; and a post mortim examination being obtained, it was found that the upper end of the shaft of the femur was united to the acetabulum by a firm fibrous investment, of which this is the preparation. A similar case, so far as success goes, occurred in the wards here, under the care of Dr. R. T. Corbet, now of New Zealand.

These successful cases naturally led me to think whether such operations could not be more frequently attempted with propriety; and the ever recurring failures in the treatment of hip-joint disease, not to mention its mortality, which undoubtedly is great, have impelled me towards some endeavour to avert such unfortunate results.

During last winter session, scveral cases of hip-disease in the stage of dislocation came into the wards; and I resolved to give excision a trial, hoping that I might meet with such results as had been experienced in the cases just named.

With some difficulty, I obtained the consent of my colleagues in con. sultation; and the following is the account of the cases as noted in the ward journals by my successive assistants, Drs. Brown, MIcQueen, and Caskie.

CASE I. (Reported by Dr. Caskie.)-Robert Watt, aged 13, was admitted on June 24th, $187 \mathrm{I}$, suffering from very far advanced disense of hip-joint. $\Lambda$ consultation having been called, it was decided to be $a$ suitable case for operation. On July 2oth, excision of the hip.joint was performed in the usual manner by Dr. Morton.

August Ist. There was very little discharge from the wound, but an abscess had opened on the anterior part of the thigh, from which a copious discharge flowed. Extension had lately been made by means of a weight hanging from the foot.

August 1 th. The wound looked healthy. There was not much discharge. The patient was keeping up his health well.

August 26 th. 'The limb was now put in a bracketed long splint.

Octoler $25^{\text {th. }}$. The bracketed splint was still used, but with no weights for extension, this being made in the usual fashion by plaster.
The opening on the anterior part of the thigh was still unclosed, and discharged pus copiously, requiring the dressings to be changed twice daily. The wound at the back part of the joint was still open for about three-fourths of its original extent, and also discharging pretty freely. The patient was very weak and anxemic, with little or no appe-
tite. The wound was looking indolent.

October 27th. A Sayre's splint was, at Dr. Morton's suggestion, constructed of gutta percha by $\mathrm{Dr}$. Caskie. The splint answered its purpose moderately well, with the exception that it did not keep the limb sufficiently extended; but it was found (as Dr. Morton expected) that, on the boy gettino. up, the weight of the limb itself was able to do this sufficiently. For a few days after its application the boy did not rise,
as there were no crutches for him.

October 3oth. The patient was up to-day, and walked about the ward for two hours. He was still very weak, and required to be assisted somewhat by the nurse.

November 5 th. Since last note, the patient had been up every day for two or three hours, and to-day, unassisted, he walked round the ward. The anterior wound was much improved, the discharge being diminished to about one-half its former quantity. The posterior wound, also, was much improved and diminished in size, being' now healing
kindly. The patient's general health had continued to improve steadily since getting up; he was not so anæmic, and his appetite had also much improved. It was found necessary, in order to get steadiness, to apply a bandage extending midway down the splint, and fixed upon the opposite side.

November 8th. The patient to-day walked about, and had the intention, had the day been good, of going out of doors. His appetite wound gave exit to almost no discharge ; the posterior wound was also healthy. The patient walked about resting upon the points of his toes, there being little shortening of the limb, and little deformity.

November $13^{\text {th. }}$. The patient continued to improve, and walked about daily. Since last note, he had been outside for an hour. There was little discharge from either opening; both were healthy.

REMARKS. - It will be observed that this lad was in hospital nearly a month before the operation was performed, although he was sent in by my friend Dr. Forrest expressly for the operation; the reason being that his bodily condition was so poor, and his emaciation so great, that it was considered essential to try to restore him somewhat by the good diet of the wards, and a little wine, that his chances of recovery after the operation might be enhanced. It is curious, however, to remark that his case has proved the most successful of the three that $I$ have to mention; or, rather, that he has recovered more rapidly, and was able to get out of bed at an earlier date, than his friend, whose case comes
next in order.

CASE Ir. (Reported by Dr. Caskie).-John MacNeil, aged Ir, had been admitted two years ago with morbus coxæ. The history obtained from the father was very vague. It appears that the child often screamed; and it was only several months after this that the hip-joint affection was discovered. At that time he remained in hospital five weeks, and was put on a long splint ; then went out and got about well, little if at all lame. He remained well till about six months before his admission on Nay 1 oth, I871, when he was tripped, and fell, and since had been un. able to walk, unless with crutches. On examination, there was found a general fulness of the right gluteal region; the gluteal fold was obliterated, and the head of the femur evidently dislocated into the sciatic notch. The limb was shortened; the right knee directed to the opposite knee; the foot inverted, and the great toe resting upon the great toe of the opposite foot; the body was arched when the limb lay fairly on the bed. There was not much pain, except at night, and then only
usually slight. II is appetite was good.

May $3^{I s t}$. The joint was to-day excised by $\mathrm{Dr}$. Morton; the head of the femur, the neck (which was much shortened), and a portion of the trochanter being removed. During the operation, an abscess was cut into, from which about ten ounces of pus escaped. After the opera. tion, the leg was allowed to lie in an easy position for a few days, and afterwards extended by weights, and kept in position by sand-bags.

July 20 th. There was not much discharge. His health was keeping up. The edges of the wound kept well in apposition. He had been taking, from the time of admission, cod-liver oil and syrup of iodide of

August 18 th. He had fallen off a little since last note. To-day the limb was put in a bracketed long splint.

October 25th. - The anterior wound was nearly healed, but still discharged a good amount of pus. The posterior wound looked healthy. The patient's health was tolerably good.

November Ist. The patient was fitted with one of the gutta percha imitations of Sayre's splint, similar in shape to the one used in the 